\title{
Reactive oxygen species mediate a cellular 'memory' of high glucose stress signalling
}

\author{
M. A. Ihnat • J. E. Thorpe • C. D. Kamat • C. Szabó • \\ D. E. Green • L. A. Warnke • Z. Lacza • A. Cselenyák • \\ K. Ross $\cdot$ S. Shakir $\cdot$ L. Piconi $\cdot$ R. C. Kaltreider • \\ A. Ceriello
}

Received: 4 October 2006 / Accepted: 15 March 2007 / Published online: 17 May 2007

(C) Springer-Verlag 2007

\begin{abstract}
Aims/hypothesis A long-term 'memory' of hyperglycaemic stress, even when glycaemia is normalised, has been previously reported in endothelial cells. In this report we sought to duplicate and extend this finding.

Materials and methods HUVECs and ARPE-19 retinal cells were incubated in 5 or in $30 \mathrm{mmol} / \mathrm{l}$ glucose for 3 weeks or subjected to 1 week of normal glucose after being exposed for 2 weeks to continuous high glucose. HUVECs were also treated in this last condition with
\end{abstract}

\author{
A. Ceriello \\ Warwick Medical School, University of Warwick, \\ Coventry, UK \\ M. A. Ihnat · J. E. Thorpe - C. D. Kamat - D. E. Green • \\ L. A. Warnke $\cdot$ K. Ross $\cdot$ S. Shakir \\ Department of Cell Biology, \\ University of Oklahoma Health Sciences Center, \\ Oklahoma City, OK, USA \\ C. Szabó $\cdot$ Z. Lacza $\cdot$ A. Cselenyák \\ Department of Surgery, \\ University of Medicine and Dentistry of New Jersey, \\ Newark, NJ, USA \\ L. Piconi \\ Morpurgo-Hofman Research Laboratory on Aging, \\ Udine, Italy \\ R. C. Kaltreider \\ Department of Biology, York College of Pennsylvania, \\ York, PA, USA
}

\section{A. Ceriello $(\bowtie)$}

Clinical Science Research Institute, Clinical Science Building,

University Hospital, Warwick Medical School,

Walsgrave Campus, Clifford Bridge Road,

Coventry CV2 2DX, UK

e-mail: antonio.ceriello@warwick.ac.uk several antioxidants. Similarly, four groups of rats were studied for 3 weeks: (1) normal rats; (2) diabetic rats not treated with insulin; (3) diabetic rats treated with insulin during the last week; and (4) diabetic rats treated with insulin plus $\alpha$-lipoic acid in the last week.

Results In human endothelial cells and ARPE-19 retinal cells in culture, as well as in the retina of diabetic rats, levels of the following markers of high glucose stress remained induced for 1 week after levels of glucose had normalised: protein kinase $\mathrm{C}-\beta, \mathrm{NAD}(\mathrm{P}) \mathrm{H}$ oxidase subunit $\mathrm{p} 47 \mathrm{phox}, \mathrm{BCL}-2-$ associated $\mathrm{X}$ protein, 3-nitrotyrosine, fibronectin, poly(ADPribose) Blockade of reactive species using different approaches, i.e. the mitochondrial antioxidant $\alpha$-lipoic acid, overexpression of uncoupling protein 2, oxypurinol, apocynin and the poly(ADP-ribose) polymerase inhibitor PJ34, interrupted the induction both of high glucose stress markers and of the fluorescent reactive oxygen species (ROS) probe CM$\mathrm{H}_{2}$ DCFDA in human endothelial cells. Similar results were obtained in the retina of diabetic rats with $\alpha$-lipoic acid added to the last week of normalised glucose.

Conclusions/interpretation These results provide proofof-principle of a ROS-mediated cellular persistence of vascular stress after glucose normalisation.

Keywords Antioxidants · Diabetic complications · Endothelial cells $\cdot$ Endothelial dysfunction .

Hyperglycaemia $\cdot$ Memory $\cdot$ Oxidative stress $\cdot$ Retinal cells . Retinopathy

$\begin{array}{ll}\text { Abbreviations } \\ \text { ALA } & \alpha \text {-lipoic acid } \\ \text { Bax } & \text { Bcl-2-associated X protein } \\ \text { BCL-2 } & \text { B cell lymphoma protein-2 } \\ \text { 3-NY } & \text { 3-nitrotyrosine } \\ \text { PAR } & \text { poly(ADP-ribose) }\end{array}$


PARP poly(ADP-ribose) polymerase

PKC protein kinase $\mathrm{C}$

ROS reactive oxygen species

UCP2 uncoupling protein 2

\section{Introduction}

The hallmark of diabetes is hyperglycaemia, which, evidence suggests, plays a major role in the pathogenesis of the disease's complications, both micro and macrovascular in nature [1].

Dysfunction of the endothelium is an integral cause of development of diabetic vascular disease [2], with many studies confirming that high glucose in vitro can directly affect endothelial cell function [3]. Recently, an excess of reactive oxygen species (ROS) generated in the endothelium and in target organs such as the retina, kidney and heart in response to hyperglycaemia has been shown to form a causative link between high glucose and diabetic complications [4, 5]. In particular, endothelial dysfunction in diabetes has been found to be mediated through an excess of cellular ROS [4] involving respiratory chain uncoupling [5], protein kinase $\mathrm{C}(\mathrm{PKC})$ activation [6], NAD $(\mathrm{P}) \mathrm{H}$ oxidase activation [4], formation of single strand DNA breaks and activation of poly(ADP-ribose) (PAR) polymerase (PARP) [7], basement membrane thickening [8] and activation of pro-apoptotic proteins [9].

Almost 20 years ago, the laboratory of Lorenzi showed that there was a persistence or 'memory' of the induced expression of basement membrane mRNAs (fibronectin, collagen IV) long after high glucose levels were normalised in endothelial cells in culture $[10,11]$ and in diabetic rats [11], suggesting the possibility of a long-lasting deleterious effect of hyperglycaemia on these cells, independent of the actual level of glucose. These data are consistent with findings that retinopathy progression can persist in dogs even after the normalisation of glycaemic control [12].

The aim of this study was to duplicate the previous findings in endothelial cells, retinal cells and in the retina of diabetic animals, and to evaluate the possible role of the persistence of ROS production after glucose normalisation as a possible explanation for the phenomenon termed here 'memory.'

\section{Materials and methods}

'Memory' experiments in cells HUVECs were grown in MCDB-131 medium (GIBCo Life Technologies, Grand Island, NY, USA) with $15 \%$ cosmic calf serum (HyClone, Logan, UT), epidermal growth factor $(10 \mathrm{ng} / \mathrm{ml}$; Peprotech, Rocky Hill, NJ, USA) and penicillin/streptomycin. ARPE-
19 cells (American Type Culture Collection, Manassas, VA, USA) were grown in DMEM with $10 \%$ cosmic calf serum (HyClone) and penicillin/streptomycin. As previously described [11], cells were incubated in $5 \mathrm{mmol} / 1$ glucose, with $25 \mathrm{mmol} / \mathrm{l}$ mannitol (Sigma Chemical, St Louis, MO, USA) for osmolarity normalisation, or in $30 \mathrm{mmol} / \mathrm{l}$ glucose for 3 weeks or up to 1 week in normal glucose $(5 \mathrm{mmol} / \mathrm{l})$ after being exposed for 2 weeks to continuous high glucose ( $30 \mathrm{mmol} / \mathrm{l})$. Fresh medium was added to cells every other day and $24 \mathrm{~h}$ before the end of the experiment.

Effects of ROS inhibition on the 'memory' phenomenon in HUVECS In the last week of normal glucose in HUVECs, glucose was given with or without agents capable of inhibiting ROS production as follows: $62.5 \mu \mathrm{mol} / 1 \alpha$-lipoic acid (ALA), an antioxidant working also at the mitochondria level [13]; $10 \mu \mathrm{mol} / 1$ apocynin [14]; $10 \mu \mathrm{mol} / 1$ oxypurinol [15]; $1 \mu \mathrm{mol} / 1 \mathrm{PJ} 34$ [16]; and 25 to 100 plaque-forming units per cell of an uncoupling protein 2 (UCP2) overexpressing adenovirus, used to specifically inhibit mitochondrial ROS production [17]. Inhibitors were replaced every other day and $24 \mathrm{~h}$ before the end of the experiment. Inhibitors were purchased from EMD Bioscience (San Diego, CA, USA), except oxypurinol and ALA, which were from Sigma Chemical and the UCP2 adenovirus, which was a kind gift of M. H. Zou (Department of Medicine, University of Oklahoma Health Sciences Center, Oklahoma, OK, USA). Cells were grown at 25 to $30 \%$ confluence in 25 or $75 \mathrm{~cm}^{2}$ flasks until $100 \%$ confluent.

Rat streptozotocin-induced hyperglycaemia mode All animal studies were conducted in accordance with guidelines approved by the Association for Assessment and Accreditation of Laboratory Animal Care International using a protocol approved by the Institutional Animal Care and Use Committee at the University of Oklahoma. To make 6- to 8-week-old female Brown Norway rats (Charles River Laboratories, Wilmington, MA, USA) hyperglycaemic, a single intraperitoneal injection of $50 \mathrm{mg} / \mathrm{kg}$ streptozotocin (Sigma Chemical) in $10 \mathrm{mmol} / \mathrm{l}$ citrate buffer, $\mathrm{pH} 4.5$, was given as previously described [18]. Similarly to cell experiments, four groups of rats were studied for 3 weeks: (1) normal rats; (2) diabetic rats not treated with insulin; (3) diabetic rats treated with insulin during the last week; and (4) diabetic rats treated with insulin plus ALA during the last week. Rats receiving insulin were implanted with a continuous-release insulin implant (LinShin, Scarborough, ONT, Canada) [19] under the skin of the upper abdomen. Blood glucose levels were in the following ranges: $5.8-8.0 \mathrm{mmol} / 1$ in non-diabetic rats, $17-$ $22.8 \mathrm{mmol} / \mathrm{l}$ in diabetic rats and $4.8-5.6 \mathrm{mmol} / 1$ in the last week of treatment in insulin-treated animals. ALA (racemic mixture; Sigma Chemical) was prepared in $0.9 \%$ sodium chloride, $\mathrm{pH} 7.4$, snap-frozen, stored at $-80^{\circ} \mathrm{C}$ and aliquots 
Fig. 1 Evidence of a persistent induction of the high glucose stress markers fibronectin (a), phospho PKC $\alpha / \beta$ II (b), p47phox (c), Bax (d), 3-NY (e) and PAR (f) in HUVECs. HUVECs were cultured in normal $(5 \mathrm{mmol} / \mathrm{l} ; \mathrm{N})$ or high $(30 \mathrm{mmol} / \mathrm{l} ; \mathrm{H})$ glucose for 3 weeks or for 2 weeks in high (30 $\mathrm{mmol} / \mathrm{l})$ glucose followed by normal $(5 \mathrm{mmol} / \mathrm{l})$ glucose for 1 week $(\mathrm{H} \rightarrow \mathrm{N})$. Whole-cell lysates were made and western blots run against high glucose stress proteins as described (Materials and methods). Data are from two separate experiments, $n=3-5$ flasks of cells. Data represent the mean \pm SEM of the densitometry of bands as a percentage of cells incubated in $\mathrm{N}$ for 3 weeks. ${ }^{*} p<0.05$; $* * p<0.01 ; * * * p<0.001$ vs HUVECs cultured in $5 \mathrm{mmol} / 1$ glucose for 3 weeks a
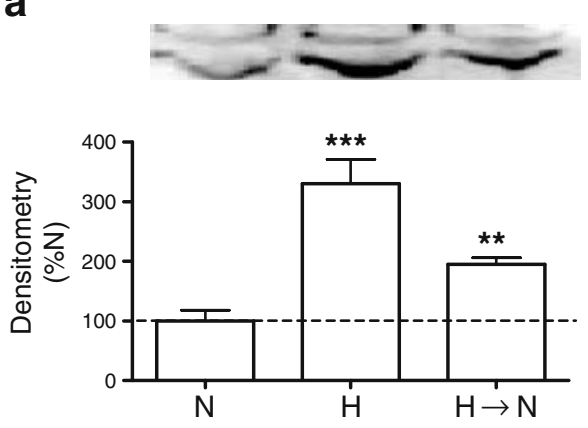

C

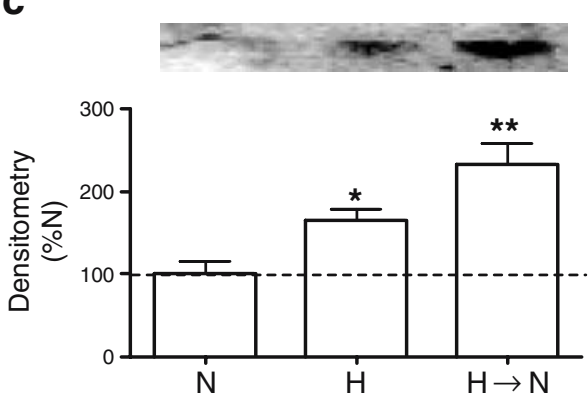

e
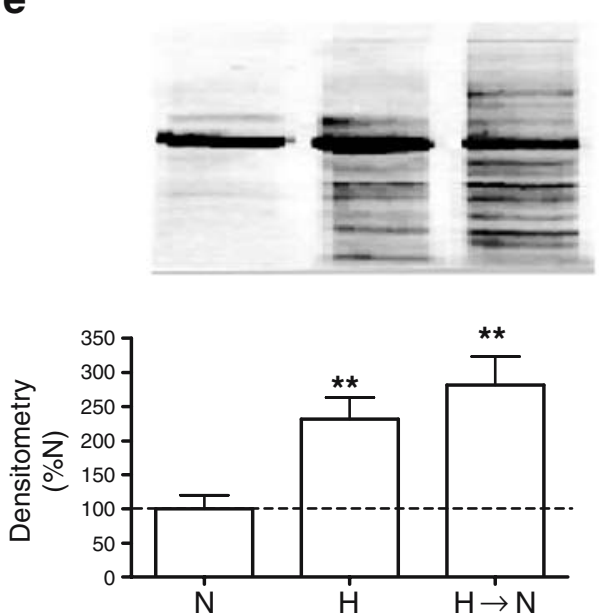

b

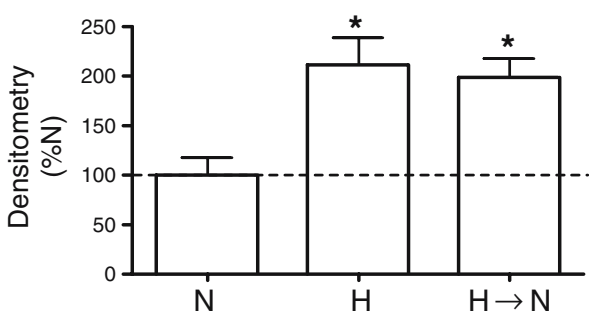

d

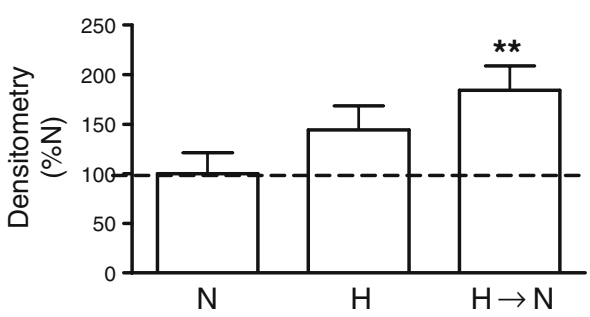

f
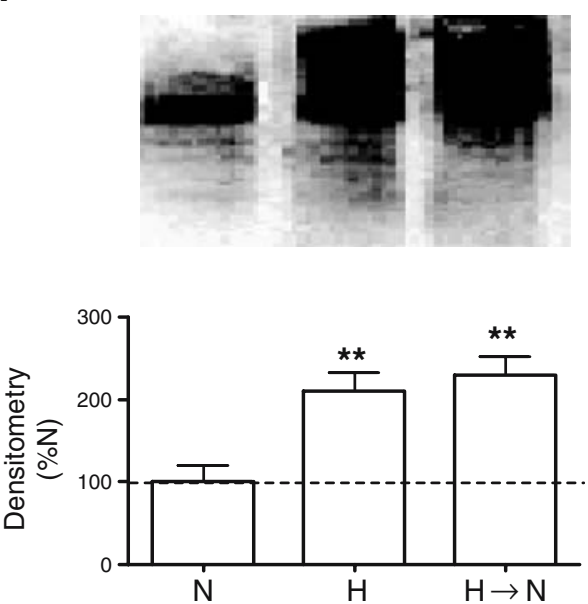

thawed daily just before injection [20]. Animals receiving ALA were injected intraperitoneally with $75 \mathrm{mg} / \mathrm{kg}$ ALA each day, while all other animals received daily injections of $0.9 \%$ sodium chloride, $\mathrm{pH}$ 7.4. Blood glucose of animals receiving insulin and ALA during the last week was $16.0-22.2 \mathrm{mmol} / \mathrm{l}$ during the first 2 weeks and $6.0-8.8 \mathrm{mmol} / \mathrm{l}$ in the last week.

Western blot analysis Whole-cell lysates were made using M-PER lysis buffer (Pierce Chemical, Rockford, IL, USA) for endothelial cells with $300 \mathrm{mmol} / \mathrm{l}$ sodium chloride and containing protease inhibitor cocktail (EMD Bioscience) and phosphatase inhibitors (Sigma Chemical). Equal amounts of protein lysates (30 or $50 \mu \mathrm{g}$; determined by Pierce micro BCA protein assay) were separated using 8$12 \%$ SDS-PAGE gels, transferred to $0.2 \mu \mathrm{mol} / 1$ nitrocellu- lose (Schleicher and Schuell, Keene, NH, USA), blocked in SuperBlock (Pierce Chemical), incubated with primary antibodies, either overnight at $4^{\circ} \mathrm{C}$, or for $2 \mathrm{~h}$ at room temperature, washed three times in Tris-buffered saline to which $0.25 \%$ Tween-20 secondary antibodies (Pierce Chemical) was added, washed again with $0.25 \%$ Tween20, to which SuperSignal Dura chemiluminescence substrate (Pierce Chemical) was added and subjected to digital imaging using a charge-coupled device camera (ImageStation 4000; Kodak, New Haven, CT, USA). Densitometry of bands was measured using Image J 1.30 analysis software (http://rsb.info.nih.gov/nih-image/). In all cases, confirmation of equal loading was performed by Memcode staining (Pierce Chemical) and by probing blots against vinculin [21]. Primary antibodies and dilutions used were 
a
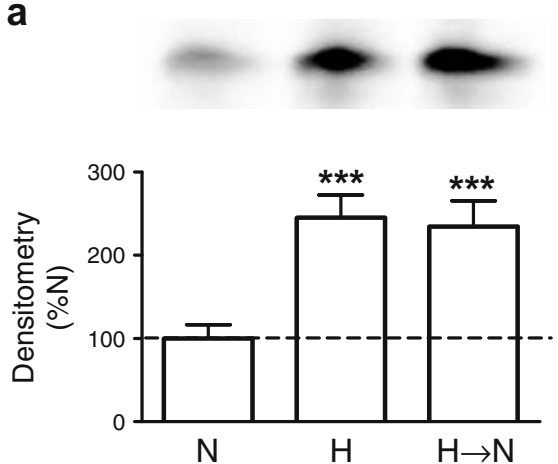

d
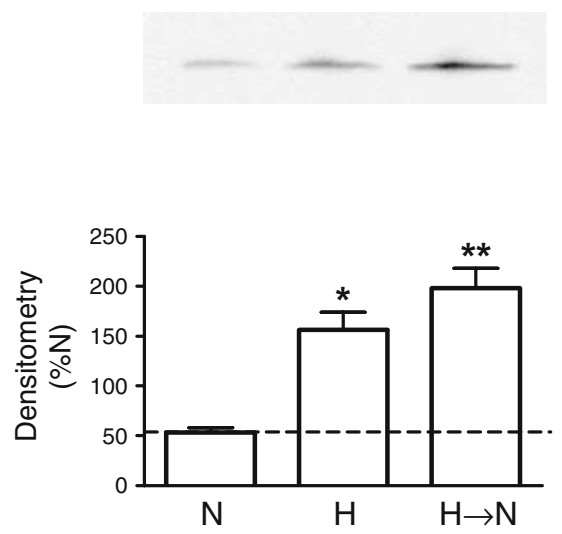

Fig. 2 Evidence of a persistent induction of the high glucose stress markers fibronectin (a), phospho PKC $\alpha / \beta I I$ (b), p47phox (c), Bax (d), 3-NY (e) and PAR (f) in ARPE-19 cells. ARPE-19 cells were cultured in normal $(5 \mathrm{mmol} / \mathrm{l} ; \mathrm{N})$ or high $(30 \mathrm{mmol} / \mathrm{l} ; \mathrm{H})$ glucose for 3 weeks or for 2 weeks in high $(30 \mathrm{mmol} / \mathrm{l})$ glucose followed by normal $(5 \mathrm{mmol} / \mathrm{l})$ glucose for 1 week $(\mathrm{H} \rightarrow \mathrm{N})$. Whole-cell lysates were made and treated

as follows: 3-nitrotyrosine (3-NY) (1:100; Upstate Biotech, Lake Placid, NY, USA); B cell lymphoma protein-2 (BCL-2)associated X protein (Bax) $(1: 1,000$; Cell Signaling Technology, Danvers, MA, USA); fibronectin human (H-300, 1:100; Santa Cruz Biotechnology, Santa Cruz, CA, USA); manganese superoxide dismutase (1:650; Abcam, Cambridge, MA, USA); p47phox human (1:500; Upstate Biotech); PAR (1:400; Alexis Biochemicals, San Diego, CA, USA); phospho PKC- $\alpha / \beta$ II (1:1,000; Cell Signaling); PKC- $\beta$ II (1:200; Santa Cruz).

CM- $\mathrm{H}_{2}$ DCFDA ROS fluorescence assay HUVECs were exposed for 3 weeks to 5 or $30 \mathrm{mmol} / 1$ glucose or for 2 weeks to $30 \mathrm{mmol} / \mathrm{l}$ glucose, followed by 1 week in $5 \mathrm{mmol} / 1$ glucose with or without inhibitors as described above. The day preceding the end of the experiment, HUVECs were plated at a density of 7,000 cells ( $70 \%$ confluence) on to white 96 -well microplates with clear bottoms (3610; Costar, Cambridge, MA, USA) in $5 \mathrm{mmol} / \mathrm{l}$ with or without inhibitors. At the end of the experiment, medium was removed from the cells and $2 \mu \mathrm{g} / \mathrm{ml}$ of the cell-permeable CM- $\mathrm{H}_{2}$ DCFDA probe (Molec-
C
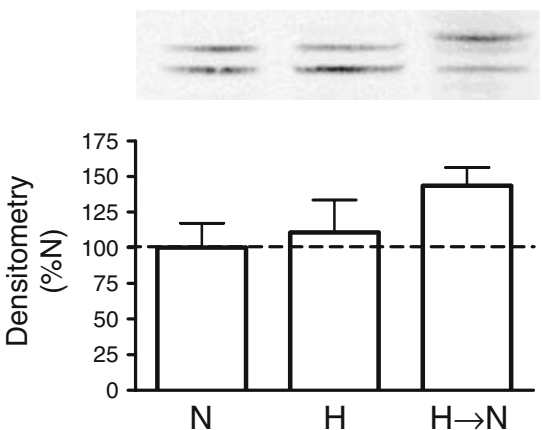

f
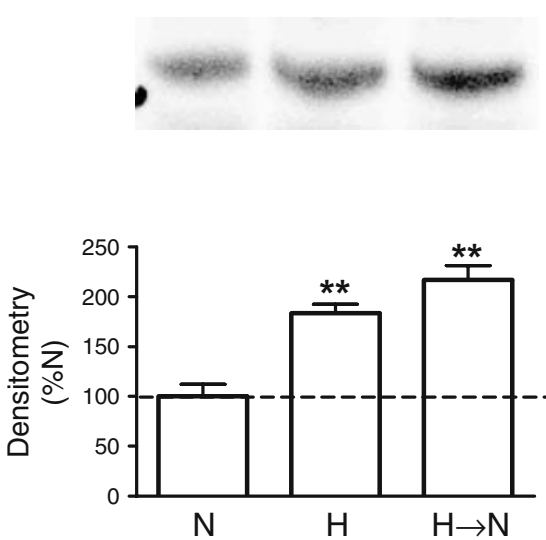

as in Fig. 1. Data are from two separate experiments, $n=3-4$ flasks of cells. Data represent the mean \pm SEM of the densitometry of bands as a percentage of cells incubated in $\mathrm{N}$ for 3 weeks. ${ }^{*} p<0.05$; ${ }^{* *} p<0.01$; $* * * p<0.001$ vs ARPE-19 cells cultured in $5 \mathrm{mmol} / 1$ glucose for 3 weeks

ular Probes-Invitrogen, Eugene, OR, USA) in Hank's Balanced Salt Solution was added to each well of the plates and incubated for $15 \mathrm{~min}$ at $37^{\circ} \mathrm{C}$ as previously described [22]. Fluorescence intensity was then measured using a plate reader (BMG Labtech, Durham, NC, USA) using $488 \mathrm{~nm}$ excitation and $530 \mathrm{~nm}$ emission filters.

Statistics Data were analysed using one-way ANOVA to compare the means of all the groups. The Neuman-Keuls multiple comparisons procedure was used to determine which pairs of means were different. Differences were considered significant at $p<0.05$.

\section{Results}

Persistence of high glucose stress markers after glucose normalisation in endothelial and retinal cells We first wished to examine whether there was a persistence or a 
Fig. 3 Effect of inhibitors given during the normalisation period on the persistence of induction of the high glucose stress markers fibronectin (a), phospho PKC $\alpha / \beta I I$ (b), p47phox (c), Bax (d), 3-NY (e) and PAR (f). Human endothelial cells were incubated $(n=8-9)$ with or without the following inhibitors during the last week of normalised glucose: $62.5 \mu \mathrm{mol} / 1 \mathrm{ALA}$, 25-100 plaque-forming units/ cell UCP2, $10 \mu \mathrm{mol} / 1$ apocynin (APO), $10 \mu \mathrm{mol} / 1$ oxypurinol (OXY) or $1 \mu \mathrm{mol} / 1 \mathrm{PJ} 34$. Western blots were performed on cellular lysates. Data represent the mean \pm SEM of the densitometry of bands as a percentage of cells incubated in high glucose $(\mathrm{H})$ for 2 weeks followed by normal glucose $(\mathrm{N})$ for 1 week $(\mathrm{H} \rightarrow \mathrm{N}) . * p<0.05 ; * * p<$ $0.01 ; * * * p<0.001$ vs cells incubated in high glucose for 2 weeks followed by 1 week of normal glucose

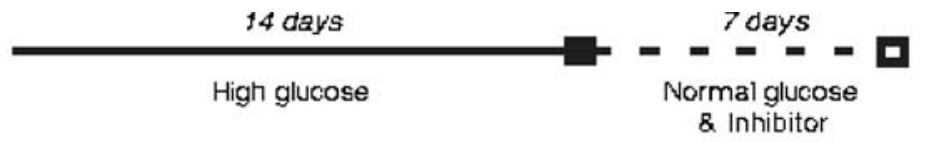

a
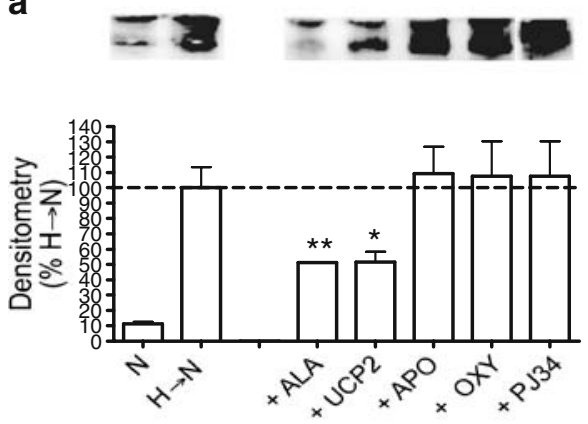

C

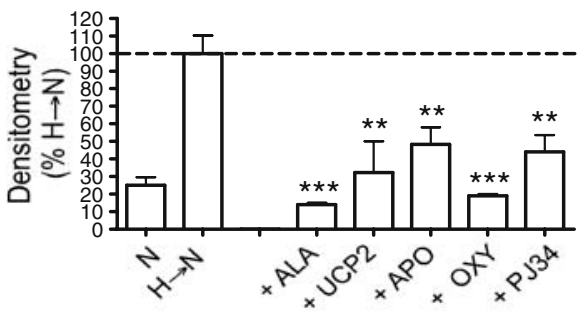

e
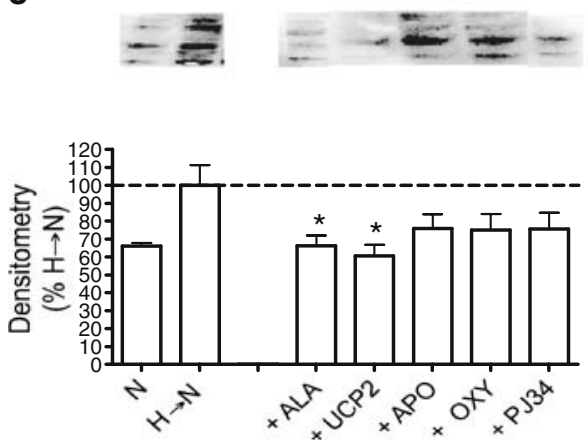

b
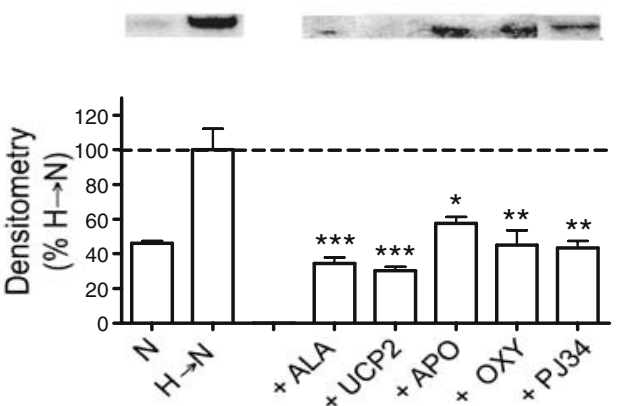

d

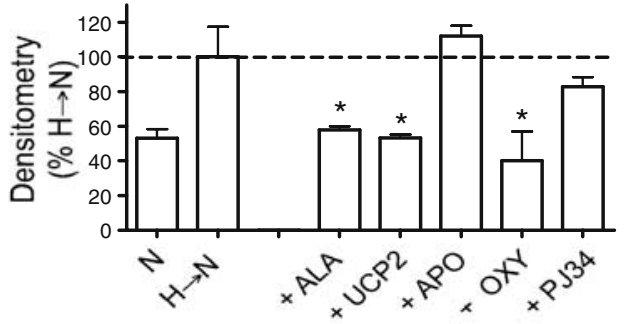

f
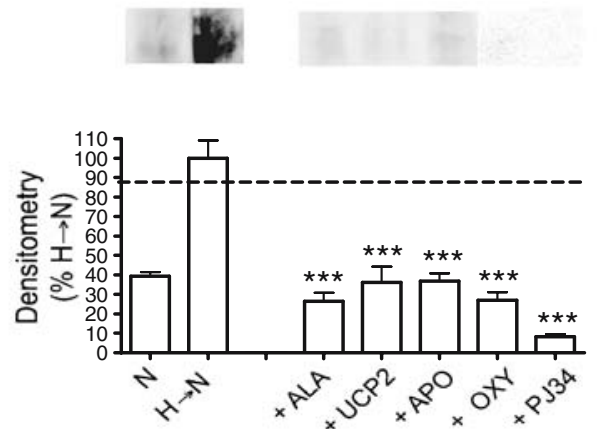

cellular 'memory' of hyperglycaemic stress after glucose levels normalised. Six different markers of high glucose stress were then measured (Fig. 1), compared with exposure to continuous normal glucose or high glucose. The markers chosen were: (1) the basement membrane protein fibronectin, shown to be overexpressed in the vessels of diabetic patients [23]; (2) the signalling kinase PKC- $\beta$, stimulated by high glucose through a cofactor, diacylglycerol [24, 25]; (3) the mitochondrial pro-apoptotic protein BCL-2 family member Bax, indicative of mitochondrial stress [26] and associated with vascular diabetic complications [27]; (4) the DNA damage protein PAR, a product of PARP, shown to be a critical factor in the development of vascular diabetic complications [7]; (5) p47phox, an inducible subunit of the enzyme NAD(P)H oxidase, shown to be a source of ROS in the endothelium of diabetic patients [28]; and (6) the protein adduct 3-NY, a marker of oxidative stress and vascular diabetic complications [29-32]. As has been shown previously, chronic high glucose resulted in significantly increased levels of: fibronectin [10]; phospho(activated) PKC- $\alpha / \beta$ II [25]; p47phox [33]; and 3-NY [31], while the increase in Bax was not statistically significant [27] (Fig. 1). As previously reported, fibronectin levels remained increased 1 week after glucose normal- 


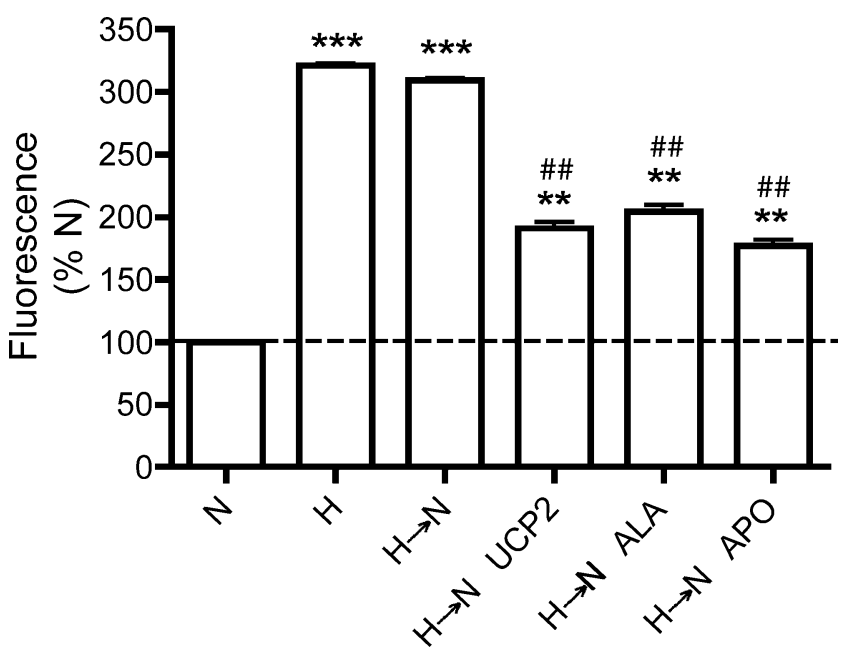

Fig. 4 Evidence of a persistent ROS build-up in HUVECs after glucose normalisation. HUVECs were cultured in normal $(5 \mathrm{mmol} / \mathrm{l}$; $\mathrm{N})$ or high $(30 \mathrm{mmol} / \mathrm{l} ; \mathrm{H})$ glucose for 3 weeks or for 2 weeks in high (30 $\mathrm{mmol} / \mathrm{l})$ glucose followed by normal $(5 \mathrm{mmol} / \mathrm{l})$ glucose for 1 week $(\mathrm{H} \rightarrow \mathrm{N})$ with or without $62.5 \mu \mathrm{mol} / 1 \mathrm{ALA}, 25-100$ plaqueforming units/cell UCP2 or $10 \mu \mathrm{mol} / 1$ apocynin (APO). Cells were loaded with $2 \mu \mathrm{g} / \mathrm{ml} \mathrm{CM}-\mathrm{H}_{2}$ DCFDA for $15 \mathrm{~min}$ at $37^{\circ} \mathrm{C}$ and fluorescence measured as in the Methods. Data are from two separate experiments, $n=3-6$ flasks of cells. Data represent the mean \pm SEM of the percentage of fluorescence of cells incubated in normal glucose for 3 weeks. $* * p<0.01 ; * * * p<0.001$ vs HUVECs cultured in $5 \mathrm{mmol} / 1$ glucose for 3 weeks. ${ }^{\#} p<0.01$ vs $\mathrm{H} \rightarrow \mathrm{N}$

isation [10]. In addition, levels of all the stress proteins measured remained significantly induced 1 week after levels of glucose were normalised (Fig. 1). Similarly, five of these six stress proteins remained induced in ARPE-19 human retinal pigment epithelial cells exposed for 2 weeks to $30 \mathrm{mmol} / \mathrm{l}$ glucose, followed by 1 week of $5 \mathrm{mmol} / 1$ glucose (Fig. 2a, b, d-f), whereas no significant induction was observed with p47phox (Fig. 2c).

The role of ROS in the 'memory' of high glucose stress in endothelial cells To explore whether decreasing levels of intracellular ROS can interrupt the cellular 'memory' of high glucose stress, an antioxidant and ROS inhibitors were added during the last week of normal glucose levels subsequent to 2 weeks of continuous high glucose. Because of the difficulty of transfecting endothelial cells and the requirement for inhibitors to be added chronically (for 1 week) after 2 weeks of high glucose, well-characterised pharmacological agents were chosen in preference to inducible genetic manipulations for expressing inhibitors. It was first found that addition of the antioxidant ALA to the last week of normal glucose resulted in significant decreases in the induction of all markers of high glucose stress (Fig. 3). Blockade of NAD(P)H oxidase by apocynin [14] or of xanthine oxidoreductase by oxypurinol [15] during the glucose normalisation period interrupted the induction of several high glucose stress markers, but not all (Fig. 3), while overexpression of the mitochondrial respi- ratory chain uncoupling protein UCP2 [17] during the normalisation period reduced the induction of all the stress proteins (Fig. 3). Finally, inhibiting the DNA damage inducible enzyme PARP during the last week of normalised glucose using PJ34 [16] interrupted the persistence of several high glucose stress markers (Fig. 3).

To examine whether free ROS remained increased after glucose normalisation, HUVECs, exposed as above, were loaded with the cell-permeable ROS-sensitive fluorescent dye CM- $\mathrm{H}_{2}$ DCFDA and fluorescence measured (Fig. 4). Exposure to $30 \mathrm{mmol} / \mathrm{l}$ continuous high glucose for 3 weeks resulted in significant induction of fluorescence compared with cells exposed to $5 \mathrm{mmol} / \mathrm{l}$ glucose, with levels of fluorescence remaining induced 1 week after glucose normalisation subsequent to 2 weeks of $30 \mathrm{mmol} / \mathrm{l}$ glucose (Fig. 4). Further, it was shown that addition of the mitochondrial uncoupling protein UCP2, the antioxidant ALA and the $\mathrm{NAD}(\mathrm{P}) \mathrm{H}$ oxidase inhibitor apocynin to the last week of normalised glucose reduced ROS-related CM- $\mathrm{H}_{2}$ DCFDA fluorescence (Fig. 4).

'Memory' of hyperglycaemic stress in the retina of diabetic animals As with the isolated endothelial cells, levels of fibronectin, activated PKC- $\beta$, p47phox, Bax, 3-NY and PAR were assessed in the retina of rats that were (1) normoglycaemic for 3 weeks or (2) hyperglycaemic for 3 weeks or (3) hyperglycaemic for 2 weeks followed by normoglycaemic for 1 week ('memory'). With the exception of Bax, the levels of these hyperglycaemic stress markers were increased in the retina of diabetic animals (Fig. 5a-c, e, f). The levels of these markers, including Bax, remained elevated for 1 week after normalisation of glucose levels (Fig. 5).

The role of ROS in 'memory' of high glucose stress in diabetic retina The next experiment was to determine whether the persistence of hyperglycaemic stress could be interrupted in the rat diabetic model in vivo, using the mitochondrial antioxidant nutritional supplement, ALA, which has previously been shown to interrupt target organ damage when given chronically to diabetic animals [20]. The addition of ALA to the last week of normalised glucose resulted in significant decreases in most of the hyperglycaemic stress markers in the retina of diabetic animals (Fig. 5).

\section{Discussion}

In this study we were able to confirm that a persistence or cellular 'memory' of high glucose stress exists after glucose levels are normalised in endothelial cells. However, for the first time, we have demonstrated that persisting overproduction of ROS may explain this phenomenon. Also, for the first time, we have found that the inhibition of 


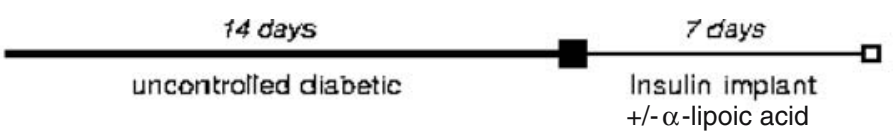

a
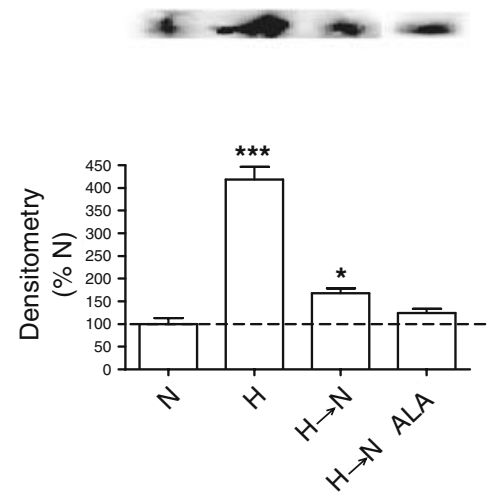

b

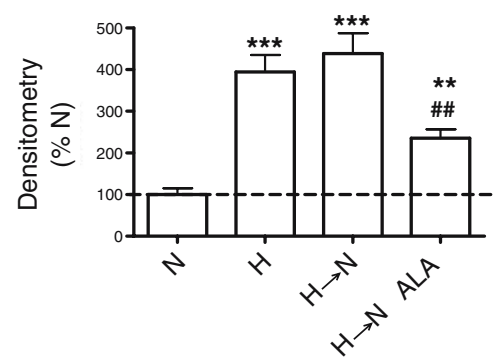

Fig. 5 Effect of glucose normalisation and ALA on the markers of hyperglycaemic stress fibronectin (a), phospho PKC $\alpha / \beta \mathrm{II}$ (b), p47phox (c), Bax (d), 3-NY (e) and PAR (f) in retina of streptozotocin-induced diabetic rats. Data, expressed as mean \pm SEM, are representative of

mitochondrial ROS production with ALA [13] or UCP2 transfection [17] can interrupt aspects of this 'memory' phenomenon. Moreover, inhibiting extra-mitochondrial ROS production or PARP activity also reduced several, but not all, of the persistently induced stress markers.

There is convincing evidence for the notion that a persisting increase of ROS generation provides the mechanistic basis underlying the hyperglycaemic 'memory' of high glucose stress marker induction. The fact that the general antioxidant ALA, which works at the mitochondrial level [13], was capable of disrupting the 'memory' for all of the high glucose stress markers in isolated endothelial cells and rat retinas as well as the induction of free ROS in endothelial cells, supports this hypothesis. Moreover, the differential effects of inhibiting mitochondrial ROS compared with extra-mitochondrial ROS in endothelial cells suggest that the persistence of the 'memory' phenomenon is related to a mitochondrial effect of hyperglycaemia. This is e

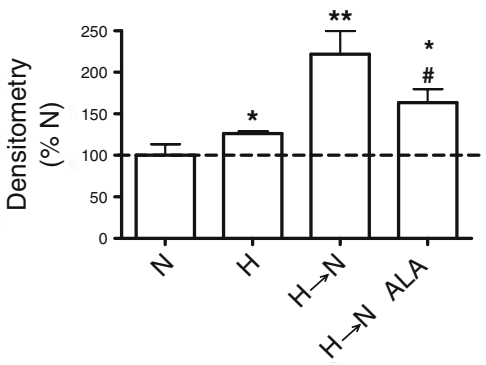

f

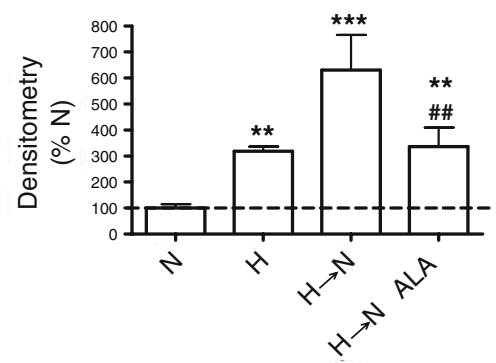

two separate experiments, $n=7-11$ rat retinas. ${ }^{*} p<0.05$; $* * p<0.01$; $* * * p<0.001$ vs organs of rats made hyperglycaemic for 2 weeks followed by glucose normalisation for 1 week $(\mathrm{H} \rightarrow \mathrm{N}) .{ }^{*} p<0.05$ vs $\mathrm{H} \rightarrow \mathrm{N} ;{ }^{\# \#} p<0.01$ vs $\mathrm{H} \rightarrow \mathrm{N}$. N, normal glucose; $\mathrm{H}$, high glucose

in keeping with previous findings, which have demonstrated that in conditions of high glucose mitochondrial overproduction of ROS accounts for the activation of all the other pathways involved in damaging endothelial cells, including those involved in amplifying the production of ROS, such as PKC and NAD(P)H excess [33-35].

Our data confirm the existence of a 'memory' of hyperglycaemia-induced damage in retinal cells in culture and in the retina of diabetic rats, suggesting that this phenomenon is linked to persistence of the oxidative stress. This hypothesis is consistent with a previous finding that the return to good glycaemic control in rats after 6 months of very poor control was ineffective in decreasing 3-NY levels or other markers of oxidative stress in the retina of these diabetic animals [12]. Moreover, the effect of ALA in our study supports the finding of Lin et al., showing protective effects of ALA in experimental diabetic retinopathy through the inhibition of oxidative and nitrosative stress [36]. 
The 1 week duration of the 'memory' of high glucose stress is too long to be explained by simple signalling mechanisms or the half-lives of messenger RNA or protein. Thus there must be something propagating this 'memory' phenomenon. Based on the excess of free ROS observed after glucose normalisation and the ability of different mechanisms to inhibit ROS and interrupt aspects of the persistence of high glucose stress, an excess of intracellular ROS in target cells is a likely candidate. In addition, although the particular regulatory mechanisms of the high glucose stress markers assessed in this paper differ, all of these markers are directly or indirectly induced by ROS [34, 37-42], again implicating an excess of cellular ROS in the 'memory' phenomenon. Interestingly, ALA and in particular overexpression of UCP2 were able to reduce the 'memory' effect for all the studied parameters, suggesting that persistent mitochondrial generation of ROS plays a key role in producing this phenomenon. A purely speculative explanation is the possibility that mitochondrial proteins are glycated during the 2 week exposure to high glucose. These premises are important because a recent study, for the first time, has described a direct relationship between the formation of intracellular AGE on mitochondrial respiratory chain proteins, the decline in mitochondrial function and excess formation of reactive species [43, 44]. Thus, AGEmodified mitochondrial respiratory chain proteins are prone to produce more ROS, independently of the level of glucose [43, 44], and could therefore also be propagating the 'memory.' Another possible alternative explanation is persistent activation of AGE receptors (RAGE) [45]. Further studies will be needed to explore these hypotheses.

In our study, only the inhibition of mitochondrial production of ROS seemed to completely abolish the 'memory' effect of hyperglycaemia, while the inhibition of cytoplasmic free radicals only partially interrupted this effect This is not surprising because mitochondrial generation of free radicals is considered to be only the first step of ROS generation, which can proceed through several other intracellular sources [46-48].

It is also intriguing that several markers not only failed to normalise or remain at the level reached during high glucose exposure, but in fact increased further after glucose normalisation. However, because expression of these markers has been shown to be regulated by free radical generation, the persistence of ROS production in the cells may also account for this phenomenon.

In summary, our results provide a proof-of-principle of cellular 'memory' of induction of six high glucose stress markers of basement membrane thickening, oxidative stress, cell death, cell signalling and DNA damage, as well as of free ROS in endothelial and retinal pigment epithelial cells and in the retina of diabetic rats long after glucose normalisation. Furthermore, antioxidants and inhibitors of mitochondrial ROS and to a lesser extent extra-mitochondrial ROS production were shown to interrupt aspects of this 'memory' phenomenon. These data support and extend the hypothesis that an excess of ROS is the causal link between hyperglycaemia and complications of diabetes [49]. Although the length of the experiment was very short, our data still show that 1 week of tight glucose control is not sufficient to normalise the damage induced by hyperglycaemia. Our data therefore confirm the need for early tight glycaemic control to avoid diabetic complications. At the same time, they also further strengthen the use of antioxidant agents, together with glucose normalisation, to mitigate the progression of these complications.

Acknowledgements This study was funded by a NIH/NCRR Center for Biomedical Research Excellence program project, 'Mentoring Vision Research in Oklahoma' (1P20RR017703-01), to M. A. Ihnat (promising junior investigator). It was also supported by the Hungarian National Scientific Research Fund (grants D-45933, T-049621, AT-049488) and Hungarian Health Science Council (grants 248/2003, 249/2003) to C. Szabó.

Duality of interest The authors all state that they have no conflict of interest with respect to publication of this work.

\section{References}

1. Laakso M (1999) Hyperglycaemia as a risk factor for cardiovascular disease in type 2 diabetes. Prim Care 26:829-839

2. Dandona P, Chaudhuri A, Aljada A (2004) Endothelial dysfunction and hypertension in diabetes mellitus. Med Clin North Am 88:911-931, $\mathrm{x}-\mathrm{xi}$

3. Soriano FG, Virag L, Szabo C (2001) Diabetic endothelial dysfunction: role of reactive oxygen and nitrogen species production and poly(ADP-ribose) polymerase activation. J Mol Med 79:437-448

4. Nishikawa T, Edelstein D, Du XL et al (2000) Normalizing mitochondrial superoxide production blocks three pathways of hyperglycaemic damage. Nature 404:787-790

5. Cai H, Harrison DG (2000) Endothelial dysfunction in cardiovascular diseases: the role of oxidant stress. Circ Res 87:840-844

6. Lee TS, MacGregor LC, Fluharty SJ, King GL (1989) Differential regulation of protein kinase $\mathrm{C}$ and $(\mathrm{Na}, \mathrm{K})$-adenosine triphosphatase activities by elevated glucose levels in retinal capillary endothelial cells. J Clin Invest 83:90-94

7. Garcia Soriano F, Virág L, Jagtap P et al (2001) Diabetic endothelial dysfunction: the role of poly(ADP-ribose) polymerase activation. Nat Med 7:108-113

8. Kimmelstiel P, Osawa G, Beres J (1966) Glomerular basement membrane in diabetics. Am J Clin Pathol 45:21-31

9. Kern TS, Tang J, Mizutani M et al (2000) Response of capillary cell death to aminoguanidine predicts the development of retinopathy: comparison of diabetes and galactosemia. Invest Ophthalmol Vis Sci 41:3972-3978

10. Cagliero E, Maiello M, Boeri D, Roy S, Lorenzi M (1988) Increased expression of basement membrane components in human endothelial cells cultured in high glucose. J Clin Invest 82:735-738

11. Roy S, Sala R, Cagliero E, Lorenzi M (1990) Overexpression of fibronectin induced by diabetes or high glucose: phenomenon with a memory. Proc Natl Acad Sci USA 87:404-408 
12. Engerman RL, Kern TS (1987) Progression of incipient diabetic retinopathy during good glycaemic control. Diabetes 36:808-812

13. Savitha S, Tamilselvan J, Anusuyadevi M, Panneerselvam C (2005) Oxidative stress on mitochondrial antioxidant defense system in the aging process: role of dl-alpha-lipoic acid and L-carnitine. Clin Chim Acta 355:173-180

14. Barchowsky A, Klei LR, Dudek EJ, Swartz HM, James PE (1999) Stimulation of reactive oxygen, but not reactive nitrogen species, in vascular endothelial cells exposed to low levels of arsenite. Free Radic Biol Med 27:1405-1412

15. Ichikawa H, Wolf RE, Aw TY et al (1997) Exogenous xanthine promotes neutrophil adherence to cultured endothelial cells. Am J Physiol 273:G342-G347

16. Piconi L, Quagliaro L, Da Ros R et al (2004) Intermittent high glucose enhances ICAM-1, VCAM-1, E-selectin and interleukin-6 expression in human umbilical endothelial cells in culture: the role of poly(ADP-ribose) polymerase. J Thromb Haemost 2:1453-1459

17. Zou MH, Kirkpatrick SS, Davis BJ et al (2004) Activation of the AMP-activated protein kinase by the anti-diabetic drug metformin in vivo. Role of mitochondrial reactive nitrogen species. J Biol Chem 279:43940-43951

18. Zhang SX, Sima J, Shao C et al (2004) Plasminogen kringle 5 reduces vascular leakage in the retina in rat models of oxygeninduced retinopathy and diabetes. Diabetologia 47:124-131

19. Tomita S, Li RK, Weisel RD et al (1999) Autologous transplantation of bone marrow cells improves damaged heart function. Circulation 100:II247-II256

20. Kowluru RA, Odenbach S (2004) Effect of long-term administration of alpha-lipoic acid on retinal capillary cell death and the development of retinopathy in diabetic rats. Diabetes 53:3233-3238

21. Navratil E, Couvelard A, Rey A, Hénin D, Scoazec JY (1997) Expression of cell adhesion molecules by microvascular endothelial cells in the cortical and subcortical regions of the normal human brain: an immunohistochemical analysis. Neuropathol Appl Neurobiol 23:68-80

22. Mishra DP, Pal R, Shaha C (2006) Changes in cytosolic $\mathrm{Ca}^{2+}$ levels regulate $\mathrm{Bcl}-\mathrm{xS}$ and $\mathrm{Bcl}-\mathrm{xL}$ expression in spermatogenic cells during apoptotic death. J Biol Chem 281:2133-2143

23. Dixon AJ, Burns J, Dunnill MS, McGee JO (1980) Distribution of fibronectin in normal and diseased human kidneys. J Clin Pathol 33:1021-1028

24. Abebe W, MacLeod KM (1990) Protein kinase C-mediated contractile responses of arteries from diabetic rats. $\mathrm{Br} \mathrm{J}$ Pharmacol 101:465-471

25. Lee TS, Saltsman KA, Ohashi H, King GL (1989) Activation of protein kinase $\mathrm{C}$ by elevation of glucose concentration: proposal for a mechanism in the development of diabetic vascular complications. Proc Natl Acad Sci USA 86:5141-5145

26. Korsmeyer SJ, Shutter JR, Veis DJ, Merry DE, Oltvai ZN (1993) Bcl-2/Bax: a rheostat that regulates an anti-oxidant pathway and cell death. Semin Cancer Biol 4:327-332

27. Podestà F, Romeo G, Liu WH et al (2000) Bax is increased in the retina of diabetic subjects and is associated with pericyte apoptosis in vivo and in vitro. Am J Pathol 156:1025-1032

28. Guzik TJ, Mussa S, Gastaldi D et al (2002) Mechanisms of increased vascular superoxide production in human diabetes mellitus: role of $\mathrm{NAD}(\mathrm{P}) \mathrm{H}$ oxidase and endothelial nitric oxide synthase. Circulation 105:1656-1662

29. Ceriello A, Quagliaro L, Catone B et al (2002) Role of hyperglycaemia in nitrotyrosine postprandial generation. Diabetes Care 25:1439-1443

30. Ceriello A, Quagliaro L, D'Amico M et al (2002) Acute hyperglycaemia induces nitrotyrosine formation and apoptosis in perfused heart from rat. Diabetes 51:1076-1082
31. Ceriello A, Taboga C, Tonutti L et al (2002) Evidence for an independent and cumulative effect of postprandial hypertriglyceridemia and hyperglycemia on endothelial dysfunction and oxidative stress generation: effects of short- and long-term simvastatin treatment. Circulation 106:1211-1218

32. Ceriello A, Mercuri F, Quagliaro L et al (2001) Detection of nitrotyrosine in the diabetic plasma: evidence of oxidative stress. Diabetologia 44:834-838

33. Quagliaro L, Piconi L, Assaloni R, Martinelli L, Motz E, Ceriello A (2003) Intermittent high glucose enhances apoptosis related to oxidative stress in human umbilical vein endothelial cells: the role of protein kinase $\mathrm{C}$ and $\mathrm{NAD}(\mathrm{P}) \mathrm{H}$-oxidase activation. Diabetes 52:2795-2804

34. Thies RL, Autor AP (1991) Reactive oxygen injury to cultured pulmonary artery endothelial cells: mediation by poly(ADPribose) polymerase activation causing NAD depletion and altered energy balance. Arch Biochem Biophys 286:353-363

35. Wu WS, Tsai RK, Chang CH, Wang S, Wu JR, Chang YX (2006) Reactive oxygen species mediated sustained activation of protein kinase $\mathrm{C}$ alpha and extracellular signal-regulated kinase for migration of human hepatoma cell Hepg2. Mol Cancer Res 4:747-758

36. Lin J, Bierhaus A, Bugert P et al (2006) Effect of R-(+)-alphalipoic acid on experimental diabetic retinopathy. Diabetologia 49:1089-1096

37. Sakamoto K, Yamasaki Y, Kaneto H et al (1999) Identification of oxidative stress-regulated genes in rat aortic smooth muscle cells by suppression subtractive hybridization. FEBS Lett 461:47-51

38. Siwik DA, Pagano PJ, Colucci WS (2001) Oxidative stress regulates collagen synthesis and matrix metalloproteinase activity in cardiac fibroblasts. Am J Physiol Cell Physiol 280:C53-C60

39. Korchak HM, Rossi MW, Kilpatrick LE (1998) Selective role for beta-protein kinase $\mathrm{C}$ in signaling for $\mathrm{O}_{2}^{-}$generation but not degranulation or adherence in differentiated HL60 cells. J Biol Chem 273:27292-27299

40. Sellak H, Franzini E, Hakim J, Pasquier C (1994) Reactive oxygen species rapidly increase endothelial ICAM-1 ability to bind neutrophils without detectable upregulation. Blood 83:2669-2677

41. Korsmeyer SJ, Yin XM, Oltvai ZN, Veis-Novack DJ, Linette GP (1995) Reactive oxygen species and the regulation of cell death by the Bcl-2 gene family. Biochim Biophys Acta 1271:63-66

42. Venugopal SK, Devaraj S, Yang T, Jialal I (2002) Alphatocopherol decreases superoxide anion release in human monocytes under hyperglycaemic conditions via inhibition of protein kinase C-alpha. Diabetes 51:3049-3054

43. Rosca MG, Monnier VM, Szweda LI, Weiss MF (2002) Alterations in renal mitochondrial respiration in response to the reactive oxoaldehyde methylglyoxal. Am J Physiol Renal Physiol 283:F52-F59

44. Rosca MG, Mustata TG, Kinter MT et al (2005) Glycation of mitochondrial proteins from diabetic rat kidney is associated with excess superoxide formation. Am J Physiol Renal Physiol 289:F420-F430

45. Goldin A, Beckman JA, Schmidt AM, Creager MA (2006) Advanced glycation end products: sparking the development of diabetic vascular injury. Circulation 114:597-605

46. Stuart JA, Brown MF (2006) Mitochondrial DNA maintenance and bioenergetics. Biochim Biophys Acta 1757:79-89

47. Kang D, Hamasaki N (2003) Mitochondrial oxidative stress and mitochondrial DNA. Clin Chem Lab Med 41:1281-1288

48. Gutierrez J, Ballinger SW, Darley-Usmar VM, Landar A (2006) Free radicals, mitochondria, and oxidized lipids: the emerging role in signal transduction in vascular cells. Circ Res 99:924-932

49. Brownlee M (2001) Biochemistry and molecular cell biology of diabetic complications. Nature 414:813-820 